\title{
WhatsApp as a Source of Support for Parents of Autistic Children
}

\author{
Rofiza Aboo Bakar, Jazredal Aboo Bakar
}

\begin{abstract}
SPARISK Support Group is a WhatsApp support group which offers parents of children with Autism Spectrum Disorder (ASD) who enrol their children in a water therapy programme a platform to discuss various issues regarding caring for their autistic children. Advanced growth in technology has improved the prospect for these parents to share information and provide support. $A$ qualitative phenomenological design was used in this study to explore the support these parents offered each other through the use of WhatsApp as a social media support group. Convenience sampling was used to select four participants who had either a child or children diagnosed with ASD who were between the ages of 7 and 16 years old, had been involved in the support group for 6 months, and lived in Penang, Malaysia. Data analysis discovered five emergent themes: (a) types of supplement and food suitable for autistic children, (b)positive experiences, (c) feeling glad, (d) informational support and (e) emotional support. Findings indicate giving the right supplement and food to autistic children and relating autistic children's positive experiences while undergoing the water therapy programme were the main functions of the group, and having water therapy coaches answering their doubts as a valuable resource. It is suggested that the use of a social media support group on WhatsApp may provide continuous support to parents of autistic children, suggesting that the formation of similar groups on other social media platforms.
\end{abstract}

Keywords: WhatsApp Support Group; Parents of Autistic Children; SPARISK.

\section{INTRODUCTION}

Autism Spectrum Disorder (ASD) affects about 60 in every 10,000 children worldwide (1). In Malaysia, it was reported that around 47,000 children suffer from ASD (2).

ASD encompasses a broad range of neuropsychological conditions that affect both individual and social functioning (3). The diagnosis of ASD is principally clinical and supported by observations of the child, interviews with the parents and uses of particular tools for screening tests (4). Individuals diagnosed with ASD normally display deficiencies in three areas: social interaction, communication skills and physical skills (5). Generally, autistic children show disruptive behaviours like yelling, humming and hitting $(6,7)$ besides having poor eye-contact, low social responses and connection $(8,9)$. They prefer strict

Revised Manuscript Received on September 22, 2019

Rofiza Aboo Bakar, Senior Lecturer, Akademi Pengajian Bahasa, Universiti Teknologi MARA, Cawangan Pulau Pinang, 13500 Permatang Pauh, Seberang Perai, Penang, Malaysia rofiza@uitm.edu.my

Jazredal Aboo Bakar, Principal, Muslim Swimming and Sports Academy, 58 Lorong Penaga 30, Taman Penaga, 13100 Penang, Malaysia. routines (10) like ordering their parents to follow the exact plans they have outlined. Changes in routines will result in tantrums. Another characteristic is they may have special obsessions (10) like eating the same food every day.

ASD is a multifaceted disorder (11). As such, parents experience frustrations when caring for, trying to understand, and interacting with autistic children (8). They normally undergo high levels of stress (12). Some feel guilty of not doing enough for their children; however some others realize that even if their children have limitations, these children may be able to achieve success in their own ways if there are patient and motivating teachers, a positive environment, and scientifically-proven interventions to help them (13).

Research reveals that these parents are in dire need to connect with other parents of autistic children so they can ask questions and share experiences (14). Forming a social support group among them is important as it may help them manage stress, and share with others their common experiences, practical information and successful coping strategies.

Recent research has also suggested that water therapy activities can: (a) increase autistic children's eye-contact, attention, confidence, social skills, balance and muscle strength; (b) allow them to stimulate their senses, vocalization and language; (c) minimize their stereotypical behaviours; (d) and let them practise movement skills (15-18). Swimming can be useful for autistic learners as it can develop their social interactions, communication skills and physical skills (19). Realizing these benefits, a water therapy programme called SPARISK (Spatial and Risk Awareness), that is specifically designed to help autistic learners know about spaces and risks in the swimming pool, increase their muscle strength, practise movement skills, and stimulate their eye-contact, attention and vocalization, has been developed. The therapy programme is developed and executed by a swimming club in Penang, Malaysia that is affiliated to the Malaysian Swimming Teachers' Association. The programme has been awarded a medal in an international innovation competition held in Malaysia. To date, there have been more than 200 autistic children registered by their parents in this programme. Some of the parents who register their children in the SPARISK programme have sought the permission from the head of the swimming club to create the SPARISK Support Group. It is a WhatsApp support group that these parents, whose inclusion is on voluntary basis, believe can offer them a 
platform to discuss various issues regarding caring for their autistic children.

Little research has been done on WhatsApp as a source of social media support group for parents of children with autism with only one such research found done in South Africa (20). Since there has been little research exploring the social support group that parents of autistic children provide to each other over an electronic device as a medium of communication, especially in Penang, Malaysia, this paper explores the support parents of autistic children offered each other through the use of a social media support group on WhatsApp.

\section{LITERATURE REVIEW}

Caring for an autistic child can be more stressful than caring for a child with normal development (12, 21). Autistic children's problems like not articulating words, exhibiting disruptive behaviours (22) and not eating well can all affect the parents adversely (23).

Emotional strain is found to be one primary challenge faced by parents, especially mothers $(4,12)$. Many mothers give up their professional careers to care for the children who often require extensive care and full commitments (24). The multiple roles they consume with limited time and energy leave them struggling to balance their roles which can lead to work-family conflict (25).

Having a social support group is one predominant coping strategy for parents of autistic children to exchange information among them (4). They are concerned about the future of their autistic children (26) and search for the availability of a multidisciplinary team which consists of educators from various fields to offer educational help to them and their children (27).

WhatsApp is a social medium introduced in 2010. In Malaysia, no study has been found researching about WhatsApp as a source of support for parents of autistic children. Only a study found about Facebook that acts as a source of support for parents of autistic children (28). However, there was a study done (29) that gave an overview of the uses of WhatsApp and Instagram in health and healthcare. These social media are regarded as effective means of people connecting with each other, allowing them to learn and have knowledge about health issues.

Qualitative research can contribute to exploring participants' experiences in depth (30). Since research on WhatsApp as a source of support for parents of autistic children is scarce, the present qualitative study aimed at focussing on the understanding of the types of support parents of autistic children experienced and offered each other through this medium.

\section{Methodology/Materials}

\section{A. Research Design and Sample Selection}

In this study, the support parents of autistic children who were enrolled in a water-therapy programme offered each other through WhatsApp was explored by using a qualitative phenomenological design. Convenience sampling was used to select four parents or participants who had either a child or children diagnosed with ASD. Only four diversified participants were chosen in this study as a qualitative phenomenological study research should not include more than four or five participants in a single study, and it is assumed that this number should offer enough data to classify themes and conduct cross-case theme analysis (31).

A letter was sent to the head of the swimming club requesting for the permission for the study to be carried out on the parents of autistic children. With her help, four participants of different races and cultures were chosen to ensure a varied sample. They had enrolled their children, whose ages were between 7 and 16 years old, in the SPARISK water therapy programme and had been involved in the SPARISK Support Group on WhatsApp for at least 6 months. Then, the participants identified were contacted and their consent to be involved in the study was sought for. All of them lived in Penang, Malaysia at the time when the study was carried out. There was no compensation given for participation in the study.

The participants were made up of: (a) Participant A, a Malay male aged 50 and whose son was 14 and had moderate autism; (b) Participant B, a Malay female aged 42 and whose sons were 12 and 16, and one had severe autism, while another moderate; (c) Participant C, a Kadazan female aged 40 and whose son was 13 and had severe autism; and (d) Participant D, a Chinese female aged 37 and whose son was 7 and had moderate autism. To ensure the confidentiality of the participants, pseudonyms were used.

\section{B. Procedure and Measures}

Data were gathered using individual semi-structured interviews. An interview instrument containing the participants' background and semi-structured questions for exploring the support they offered each other in their support group on WhatsApp was used to gather data. The questions were open-ended to allow the participants to relate their experiences and feelings in detail. Some of the interview questions included: (a) Do you think there are advantages joining the SPARISK Support Group?; (b) Can you specify the advantages or the disadvantages?; (c) What kind of support do you offer to other parents in the group?; (d) What do you think of the water-therapy programme? These questions were validated by three qualitative expert researchers whose experience performing qualitative studies were more than 15 years. While interviewing, probes, such as "please explain", "please elaborate" and "what do you mean by" where applicable and needed to increase the depth of each participant's response were used as suggested by Cohcran and Patton (2007) (as cited in 32 \& 31).

Each participant was interviewed separately. The length of each interview was between 30 and 40 minutes at a time and date specified by the participants. The interviews were audio-recorded and transcribed. To ensure validity and reliability, member checks were used (33). It means that the interview transcripts were referred back to the respective participants for accuracy

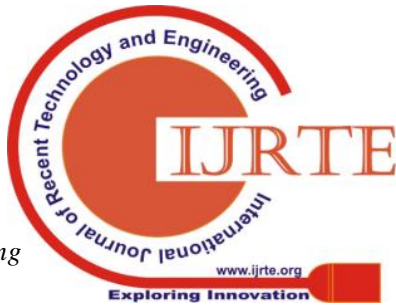


confirmation and to minimize any bias that may occur because of the researchers' influence. All transcripts were read at least twice in undisturbed periods (29) so that a sense of totality for data could be gained.

\section{Data Analyses}

The data collected were organized systematically so that meaning and realistic conclusions could be elicited and drawn (34). Interviews were transcribed verbatim as soon as possible to reduce losing valid and reliable data. The transcripts were read through, and from which identification of meaningful themes was made and written. It was found that in a sentence of the transcript, there could be more than one unit of meaning. Each unit of meaning was coded in a codebook and given a specific number and alphabet so that related types of data could be kept together to avoid confusion. The codebook consisted of the units of meanings that were grouped under major themes and sub-themes, which can still be divided into other sub-codes. For instance, a major theme may be 'Types of supplement and food suitable for autistic children'. The sub-theme may be 'Vitamin'. The sub-code may be 'Vitamin B'. There was no limit to the number of themes, but the unimportant themes were disregarded. Five important themes were reached. The themes were compared to the results obtained from similar studies so that the interpretations were accurate.

\section{RESUltS AND DiscuSSION}

\section{A. Results}

The findings of this study are discussed according to five main themes that emerged. They are (a) types of supplement and food suitable for autistic children, (b) positive experiences, (c) feeling glad, (d) informational support and (e) emotional support.

\section{1) Types of Supplement and Food Suitable for}

\section{Autistic Children}

Parents of autistic children in this study offered each other advice about feeding their children with types of food suitable for ASD. Discussions revolved around giving their children supplementary and avoiding food that could make ASD worse.

They frequently discussed that their autistic children needed suitable supplement more than certain prescribed medicine. They believed that the medicine to eliminate tantrums and hyperactivity could lead to their children experiencing cramped muscles. In contrast, they believed that giving fish oil, particularly of the Efamol Efalex brand, could result in stimulating their children's antibody and reducing gut-inflammatory. Participant A stated that "I give my son Efamol Efalex although it is very difficult for me to get it in the pharmacies nowadays. I don't mind ordering it from my friend who stays overseas".

Generally, autistic children lack concentration and can easily be impulsive. The professionally-trained water-therapy coaches advised the parents to reduce sugar and dairy products to their children since these types of food are the cause for lack of attentiveness and impulsiveness. They then discussed that they should learn more about proper food intake for their children from a Malaysian famous couple who had successfully experimented and implemented it on their child and was actively promoting free-gluten food intake Malaysian-wide. With the help of the water-therapy coaches, they were able to invite the Malaysian couple to Penang for a one-day talk.

\section{2) Positive Experiences}

The SPARISK Support Group was believed to be helpful in relating positive experiences the parents had with their autistic children while the latter were undergoing the water-therapy programme. Participant $\mathrm{C}$ confessed that she had a 'new' son who had stopped making tantrums, humming and noise. She said, "My 'new' son, unlike before, could wait calmly for food order in a restaurant for a long time without showing any signs of restlessness. He was patient. 25 minutes passed and he didn't make any noise". In addition, Participant B told the group that both her sons were happy in their recent holiday and could control their behavior by not throwing any tantrums.

They too narrated how proud and happy they were when their children could embrace certain new skills and behaviour, such as being able to cycle, uttering words and complaining about how naughty their friends were when before they were non-verbal and communicate through typing words, singing in front of others and not running away when meeting other people. To them, this happiness was similar to the feelings felt by parents with normal children getting all as in their exams.

\section{3) Feeling Glad}

All the participants in this study believed that the water therapy their autistic children were undergoing helped in their children's progress. They were glad they met the professionally-trained water therapy coaches. Participant A said, "We need this water therapy to eradicate our children's tantrums". Participant B added, "My sons are more focussed now. Could not do that without the coaches. Proud to be part of the team. May God ease everything". Participant C said, "Thank God for allowing us to meet these water therapy coaches who teach and help our kids in their development". Participant D said that "I am touched that this group provide solutions, not focusing too much on sad stories about having children with ASD".

\section{4) Informational Support}

Participants in the study sought and offered advice from each other if they were not sure about an issue. Participant A gladly told the group members how he toilet-trained his son since small. Participant B suggested that Muslim autistic children who needed to undergo circumcision could do it in the Universiti Sains Malaysia Hospital in Bertam whose fees were reasonable, and whose doctors and nurses were friendly. Participant $\mathrm{C}$ imparted her knowledge about steps to enroll autistic children in special classes provided by the Malaysian government. Participant D shared with others several websites and apps, such as the Starfall Apps

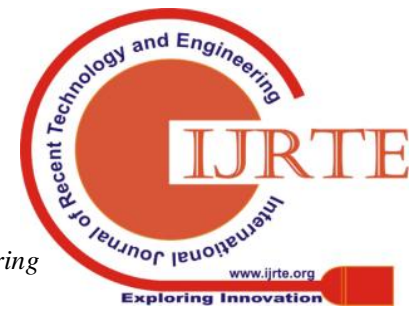


which featured simple stories with interactive and attractive pictures to teach her son sounds of words and reading.

\section{5) Emotional Support}

The participants in this study could not help but to reminisce on the sad experiences they had when they brought their children out to mingle with the society. Participant A said that once he was told to bring his son back home from the mosque, for his son was noisy and exhibited peculiar behavior. He was told by a man praying there that God would forgive both him and the son even without their coming to pray in the mosque. Participant D related that she was scolded and screamed at by a woman whose son was thrown a ball at by Participant's D son. She was reprimanded to not bring her son out in the public if she did not know how to make him behave. Participants B and C shared almost the same experiences. However, they did not want these sad stories to hinder them from finding interventions and solutions for their children. They believed the SPARISK Support Group could act as a platform for them to exchange emotional support because they believed they knew how challenging it was to raise autistic children. Together, they felt that they could make a change and educate the public about autism. Participant $\mathrm{C}$, in fact, went an extra mile by visiting some parents of autistic children to get to know them better and offer whichever support she could contribute.

\section{Conclusion}

In this study, five themes emerged from the social media support for parents of autistic children: (a) types of supplement and food suitable for autistic children, (b) positive experiences, (c) feeling glad, (d) informational support and (e) emotional support.

Consistent with Lucarelli, Frediani (35), participants suggested that removing dairy food and gluten from their autistic children's diet could increase focus besides minimizing tantrums. Next, this study demonstrated that participants shared positive experiences about their children having undergone water therapy. This correlates with a study conducted by Teske (36) who found that autistic children who underwent water therapy experienced benefits, such as an increase in eye contact, social interaction and verbal ability. Participants in this study also sought and offered informational support. This echoes with previous research done by Cole, Kharwa, Khumalo, Reinke and Karrim (19) who reported that parents want to listen and get information from others so that they could use others' experiences for the well-being of their autistic children. Connecting to others who have the same experiences is essential. These parents also relied on each other for emotional support which resonates the study done by Mustafa, Short and Fan (36) that found that parents of autistic children live with the challenges of coping with the symptoms of ASD and need to share their personal experiences with others.

Although many of the findings in this study are consistent with those of other previous studies, it has discovered one novel lesson that other parents or caretakers of autistic children may learn from. Despite all the problems faced in taking care of autistic children, harping on sad stories will not change these children's conditions. Instead, finding a suitable intervention, such as the water-therapy programme, is vital in attaining the children's well-being. They have all believed that the SPARISK programme has contributed positive changes in their children.

A limitation of this study is that the results obtained only reveal the findings from one support group in Penang, Malaysia. Thus, the types of support experienced by the parents of autistic children are related since their children undergo the same water therapy by the same professionally-trained water therapy coaches. Further research should investigate the usage of other WhatsApp groups around Malaysia and other types of social media support groups, such as Facebook and Tweeter, to provide more extensive, conclusive and on-going types of support to Malaysian parents of autistic children. Future research may also examine various types of support parents of autistic children offer in other therapy groups, such as horse therapy and occupational therapy.

\section{ACKNOWLEDGEMENTS:}

The authors would like to thank all the parents of autistic children that had participated in this study and the swimming club whose classes their children had enrolled in. This research work is partially supported by Universiti Teknologi MARA, Cawangan Pulau Pinang.

\section{REFERENCES}

[1] Lindgren S, Doobay A. Evidence-based interventions for autism spectrum disorders. The University of Iowa, Iowa. 2011.

[2] Bakar RA, Bakar JA. Understanding support for parents of autistic children through a WhatsApp group. Asia Proceedings of Social Sciences. 2019;4(2):117-20.

[3] Losh M, Adolphs R, Poe MD, Couture S, Penn D, Baranek GT, et al. Neuropsychological profile of autism and the broad autism phenotype. Archives of general psychiatry. 2009;66(5):518-26.

[4] Gomes P, Lima LH, Bueno MK, Araújo LA, Souza NM. Autism in Brazil: a systematic review of family challenges and coping strategies. Jornal de pediatria. 2015;91(2):111-21.

[5] Association AP. Diagnostic and statistical manual of mental disorders Washington, DC: 2000.

[6] Ozdemir S. The effectiveness of social stories on decreasing disruptive behaviors of children with autism: Three case studies. Journal of Autism and Developmental Disorders. 2008;38(9):1689-96.

[7] Ali S, Frederickson N. Investigating the evidence base of social stories Educational Psychology in Practice. 2006;22(4):355-77.

[8] Gray CA. Social stories and comic strip conversations with students with Asperger syndrome and high-functioning autism. Asperger syndrome or high-functioning autism? Springer; 1998. p. 167-98.

[9] Kokina A, Kern L. Social Story ${ }^{\text {TM }}$ interventions for students with autism spectrum disorders: A meta-analysis. Journal of autism and developmental disorders. 2010;40(7):812-26.

[10] Association AP. Diagnostic and statistical manual of mental disorders. Washington, DC: 2000.

[11] Koegel RL, Vernon TW, Koegel LK. Improving social initiations in young children with autism using reinforcers with embedded social interactions. Journal of autism and developmental disorders. 2009;39(9):1240-51.

[12] Dabrowska A, Pisula E. Parenting stress and coping styles in mothers and fathers of pre-school children with autism and Down syndrome. Journal of Intellectual Disability Research. 2010;54(3):266-80.

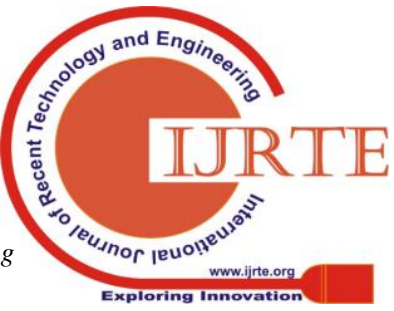


[13] Malecki C. Parenting a child with autism: Resist pressure, find success for each individual, the journey is unique. 2014. Available from: https://www.psychologytoday.com/intl/blog/the-wide-wide-world-psych ology/201409/parenting-child-autism-resist-pressure-find-success

[14] Niela-Vilén H, Axelin A, Salanterä S, Melender HL. Internet-based peer support for parents: A systematic integrative review. International journal of nursing studies. 2014;51(11):1524-37.

[15] Chien YP. Effects of water exercise swimming program on aquatic skills and social behaviors in children with autism spectrum disorders. Autism. 2010;14(9):9-28.

[16] Ennis E. The effects of a physical therapy-directed aquatic program on children with autism pectrum disorders. Journal of Aquatic Physical Therapy. 2011;19(1):4-10.

[17] Hulls DSV, Walker LK, Powell JM. Clinicians' perceptions of the benefits of aquatic therapy for young children with autism: A preliminary study. Physical \& Occupational Therapy in Pediatrics. 2006;26(1-2):13-22.

[18] Mortimer R, Privopoulos M, Kumar S. The effectiveness of hydrotherapy in the treatment of social and behavioral aspects of children with autism spectrum disorders: a systematic review. Journal of multidisciplinary healthcare. 2014;7:93

[19] Kraft E, Leblanc R. Instructing children with Autism Spectrum Disorder: Examining swim instructors' knowledge building experiences. Disability and health journal. 2018;11(3):451-5.

[20] Cole L, Kharwa Y, Khumalo N, Reinke JS, Karrim SB. Caregivers of School-aged Children with Autism: Social Media as a Source of Support. Journal of Child and Family Studies. 2017;26(12):3464-75.

[21] Ingersoll B, Meyer K, Becker MW. Increased rates of depressed mood in mothers of children with ASD associated with the presence of the broader autism phenotype. Autism Research. 2011;4(2):143-8.

[22] Pisula E. A comparative study of stress profiles in mothers of children with autism and those of children with Down's syndrome. Journal of Applied Research in Intellectual Disabilities. 2006;20(3):274-8.

[23] Dominick KC, Davis NO, Lainhart J, Tager-Flusberg H, Folstein S. Atypical behaviors in children with autism and children with a history of language impairment. Research in developmental disabilities. 2007;28(2):145-62.

[24] Marshall NL, Tracy AJ. After the baby: Work-family conflict and working mothers' psychological health. Family Relations: Interdisciplinary Journal of Applied Science. 2009;58:380-91.

[25] Sitimin SA, Fikry A, Ismail Z, Hussein N. Work-family conflict among working parents of children with autism in Malaysia Procedia Computer Science 2017;105:345-52.

[26] Koegel RL, Schreibman L, Loos LM, Dirlich-Wilhelm H, Dunlap G, Robbins FR, et al. Consistent stress profiles in mothers of children with autism. Journal of autism and developmental disorders. 1992;22(2):205-16.

[27] Benson P, Karlof KL, Siperstein GN. Maternal involvement in the education of young children with autism spectrum disorder. Autism. 2008;12:47-63.

[28] Roffeei SHM, Abdullah N, Basar SKR. Seeking social support on Facebook for children with Autism Spectrum Disorders (ASDs). International journal of medical informatics 2015 84(5):375-85.

[29] Boulos MNK, Giustini DM, Wheeler S. Instagram and Whatsapp in health and helathcare: An overview. Future Internet 2016;8(37):1-14.

[30] Bogdan R, K. BS. Qualitative research for education: An introduction to theory and methods. Boston: Allyn and Bacon; 1992.

[31] Creswell JW, Hanson WE, Clark Plano VL, Morales A. Qualitative research designs: Selection and implementation. 35. 2007;2(236-264).

[32] Cole L, Kharwa Y, Khumalo N, Reinke JS, Karrim SB. Caregivers of school-aged children with autism: Social media as a source of support. Journal of Child and Family Studies. 201726 (12):3464-75.

[33] Merriam SB. Case study research in education: A qualitative approach: Jossey-Bass; 1988.

[34] Bengtsson M. How to plan and perform a qualitative study using content analysis. Nursing Plus Open. 2016;2:8-14.

[35] Lucarelli S, Frediani T, Zingoni A, Ferruzzi F, Giardini O, Quintieri F, et al. Food allergy and infantile autism. Panminerva medica. 1995;37(3):137-41.

[36] Teske AM. Exploring hydrotherapy with autism. Honors Research Project. 2018;692.

\section{AUTHORS PROFILE}

I am Rofiza Aboo Bakar, currently I am working as Senior Lecturer, Akademi Pengajian Bahasa, Universiti Teknologi MARA, Cawangan Pulau Pinang, 13500 Permatang Pauh, Seberang Perai, Penang, Malaysia
My name is Jazredal Aboo Bakar, I am affiliated with Principal, Muslim Swimming and Sports Academy, 58 Lorong Penaga 30, Taman Penaga, 13100 Penang, Malaysia. 